\title{
Electromagnetic interference shielding in unmanned aerial vehicle against lightning strike
}

\author{
Diah Permata*, Menachem C. Gurning, Yul Martin, Henry B.H. Sitorus, \\ Mona Arif Muda, Herman H. Sinaga \\ Department of Electrical Engineering, Universitas Lampung, Lampung, \\ Jalan Soemantri Brojonegoro No. 1, 0721-704947/0721-704947, Indonesia \\ *Corresponding author, email:diah.permata@eng.unila.ac.id ${ }^{*}$
}

\begin{abstract}
Electromagnetic interference (EMI) due to lightning strike in Unmanned Aerial Vehicle (UAV) became a critical issue, since it could cause a severe damaged to electronic equipment which was installed in UAV. This paper proposed a method to reduce EMI by creating shield over the body of UAV with aluminum foil with thickness $0.15 \mathrm{~mm}$. A standard lightning impulse-voltage generated by impulse generator was delivered to the high voltage (HV) electrode at a particular distance from UAV. Indirect effect of lightning strike was investigated by measuring induced voltage inside the compartment of UAV fuselage during flashover between the HV electrode and UAV. Flashover between the HV electrode and UAV simulated the lightning strike. The result showed that the highest voltage only $1 \mathrm{~V}$ at UAV compartment when $150 \mathrm{kV}$ impulse voltage supplied to the electrode with striking area on the wing. The measured voltage was far below $100 \mathrm{~V}$ as the insulation level of low voltage equipment inside UAV. Although the direct effect of lightning has created a burning hole on the surface aluminum foil with thickness $0.15 \mathrm{~mm}$, the effect was overcome by increasing the thickness to $0.3 \mathrm{~mm}$. The application of aluminum foil over the surface of UAV repelled the electromagnetic interference which acted as a Faraday cage. The shielding method was successfully reduced the effect of EMI.
\end{abstract}

Keywords: electromagnetic interference, induced voltage, lightning strike, shielding, unmanned aerial vehicle

Copyright $@ 2019$ Universitas Ahmad Dahlan. All rights reserved.

\section{Introduction}

In general, Unmanned Aerial Vehicle (UAV) structure made of kevlar, fiberglass, carbon fiber, balsa wood, and elapor foam [1]. Those materials are dielectric which are not conductive at all, except carbon fiber which is less conductive than metal. Dielectric materials are vulnerable to lightning strikes damage. Lightning strike to aircraft has two effects: direct and indirect. Direct effect is mainly related to physical damage of the structure at the striking area [2-4]. Indirect effects occur when electromagnetic field induce transient voltages in the compartment of UAV fuselage [2, 3].

The Lightning Strike Protection (LSP) serves as a conductor path over the skin of aircraft to ground without damage and it gives shield against electromagnetic interference [5]. Due to low electrical conductivity of dielectric materials, some materials and methods have been studied to improved the conductivity [2, 6-12]. Several works proposed the use of metallic coating such as: aluminum, silver, pristine graphene or carbon based composited for LSP [6-10], or hybrid coating consisted of silver nano particles dispersed in conducting polymer [10]. Other works proposed paper made of carbon nanofiber and nickel nanostrand [2]. A conducting polymer which has a conductivity similar to metal such as (Polyaniline) was suggested by [11] as a filler of dielectric matrix. Previous researchers also used copper wire mesh or pristine as an envelop of carbon fiber composite [12]. Among all, expanded copper foil (ECF) showed as the best material used for LSP [10]. However, copper foil is heavier than aluminum. Moreover, copper is more expensive than aluminum.

Many papers have discussed the LSP solution in the aircraft but the method did not effectively overcome electromagnetic interference in UAV. The authors carried out lightning strike tested using a lightning current waveform to investigate the performance of LSP [2, 5, 8-10, 12]. While few paper proposed the LSP solution in UAV. Other works developed a numerical simulation and experimental validation method to assess 
electromagnetic compatibility of composite based UAV by using a DC injection test to measure induced current $[13,14]$. However, the test can not be used to study electromagnetic interference due to lightning strike.

Therefore, this research was to study the electromagnetic interference shielding against lightning strike. This paper proposed a method to reduce electromagnetic interference by covering body of UAV with aluminum foil. Both direct and indirect effects of lightning strikes were investigated by testing UAV under high voltage test. This research used a standard lightning impulse voltage supplied by impulse generator. The lightning impulse voltage was used instead of lightning current because this research mainly investigates the induced voltage cause by electromagetic field during lightning strike.

\section{Research Method}

The UAV Skywalker X8 with specification listed in Table 1 was used in this research. It made of elapor foam wrapped with fiberglass using lycal resin to strengthen the structure. Hence, the UAV was totally made of dielectric material. The EMI shielding made from aluminum foil with $0.15 \mathrm{~mm}$ thickness. Figure 1 shows the UAV has covered with aluminum foil.

Table 1. UAV Skywalker X8 specification

\begin{tabular}{|c|c|}
\hline Parameter & Dimension \\
\hline Wing Span & $2.122 \mathrm{~m}$ \\
\hline Wing Area & $0.8 m^{2}$ \\
\hline Payload & $1-2 \mathrm{~kg}$ \\
\hline
\end{tabular}

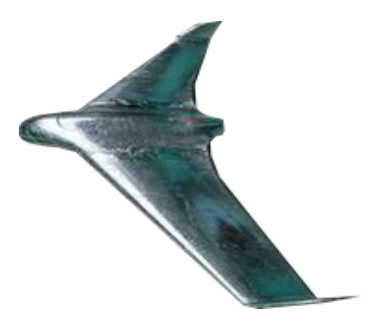

Figure 1. Application of aluminum foil on Skywalker X8 UAV to shield electromagnetic interference

The UAV which has EMI shielding was undergone high voltage (HV) testing. The aim of testing was to measure induced voltage during flashover between high voltage electrode and UAV. When flashover occurred an electromagnetic field was created in vicinity of striking point. Figure 2 shows an impulse generator used to generate lightning impulse voltage. A standard lightning impulse voltage $1.2 / 50 \mu$ s was delivered to high voltage electrode as shown in Figure 3.

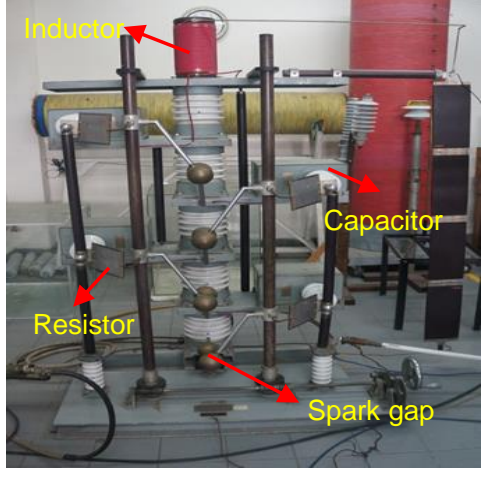

Figure 2. An impulse generator used to generate impulse voltage

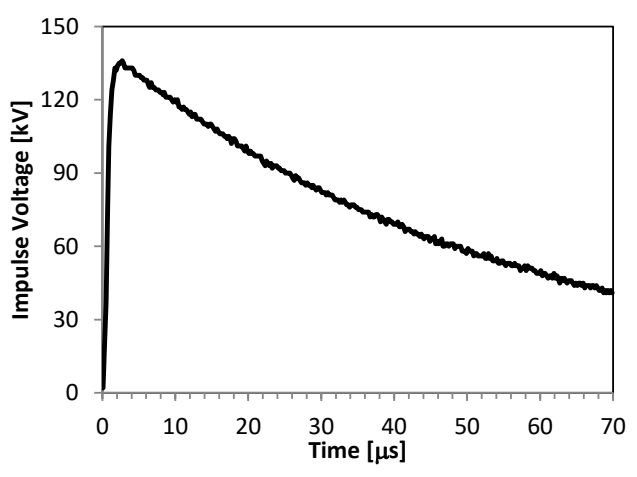

Figure 3. A standard impulse voltage $1.2 / 50 \mu$ s which is supplied to high voltage electrode

Two set-ups of experiments were carried out in this research with different purposes. The first measurement used to measure induced voltage in UAV compartment. While, the 
second measurement used to measure voltage in vicinity area of UAV. In each testing, input voltage waveform and induced voltage were measured. An oscilloscope $100 \mathrm{MHz}$ GW Instek GDS-2104 was used to capture a voltage waveform. An electrostatic field meter (EFM) Simco FMX-004 was used to measure electric field. The EFM measured electric field and it was displayed in the form of voltage at a distance of 1 inch. The measured electric field could be obtained by dividing the displayed-voltage with $2.54 \mathrm{~cm}$; hence, the unit becomes $\mathrm{V} / \mathrm{cm}$.

\subsection{Testing Electric Field in Compartment of UAV Fuselage}

Measurement set-up as shown in Figure 4(a) was to measure induced voltage inside compartment of UAV fuselage during flashover. The UAV was located below a square metal plate where a high voltage (HV) electrode was mounted. Distance between HV electrode and UAV was $1 \mathrm{~cm}$. A flashover occurred between high voltage electrode and UAV is shown in Figure 4(b), (c), and (d). This flashover simulated a lightning strike to UAV. The EFM was placed in the compartment of fuselage. The EFM was very sensitive and unstable to the change of surrounding condition. Hence, a camera also put in the compartment of fuselage to capture the displayed value at the time of flashover. There are three striking points i.e. nose, fuselage, and wing. In each striking point, the lightning impulse voltage of $100 \mathrm{kV}$ and $150 \mathrm{kV}$ were injected to the HV electrode. The experiment was carried out ten times to get the average induced voltage.

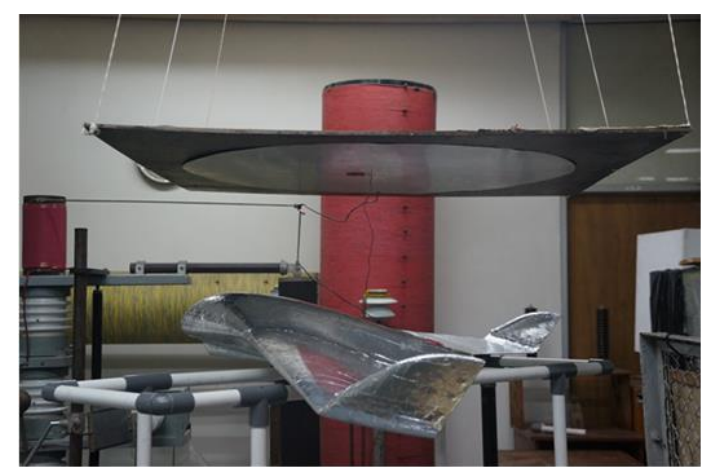

(a)

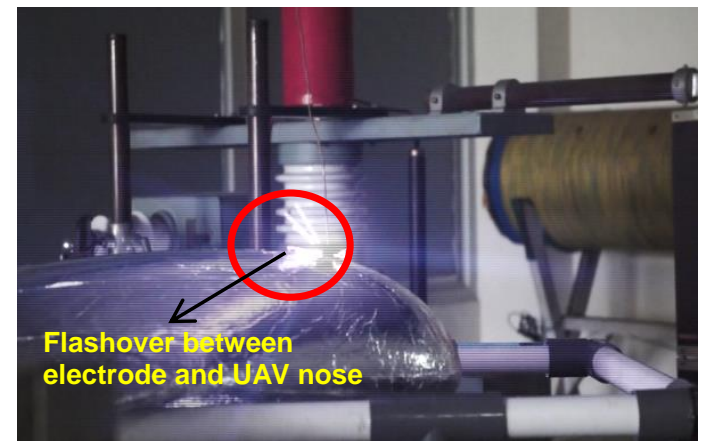

(c)

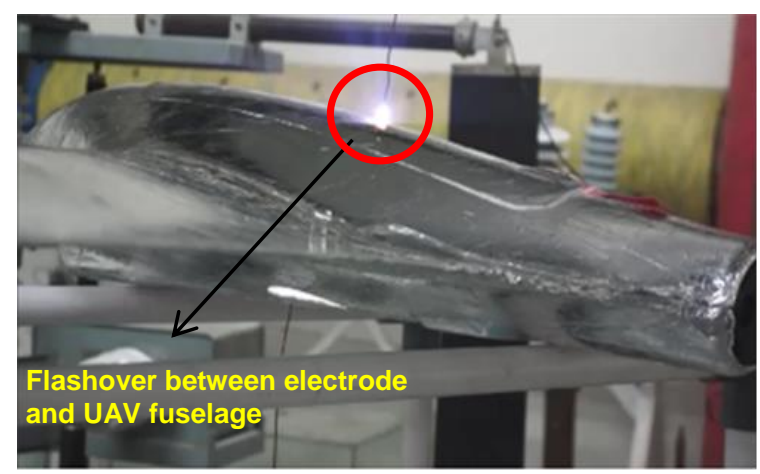

(b)

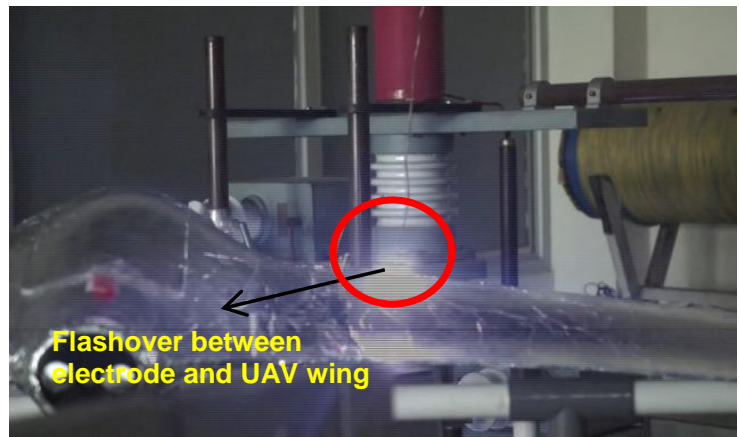

(d)

Figure 4. High voltage testing (a) Experimental set-up to measure electric field (b) Flashover on UAV fuselage at $1 \mathrm{~cm}$ distance (c) Flashover on UAV nose at $1 \mathrm{~cm}$ distance (d) Flashover on UAV wing at $1 \mathrm{~cm}$ distance

\subsection{Testing Electric Field in Vicinity Area of UAV during Flashover}

The idea of conducting the test was to measure the induced voltage inside the compartment of fuselage without EMI shielding. However, the conducted test is harmful to the electrostatic field meter. A modification has been made by placing EFM at $4 \mathrm{~cm}$ below the fuselage. A $50 \mathrm{kV}$ impulse voltage was delivered to $\mathrm{HV}$ electrode. The measured result was used to calculate the induced voltage at $1 \mathrm{~cm}$ distance between HV electrode and UAV. 


\section{Results and Discussion}

\subsection{Testing Electric Field in Compartment of UAV Fuselage}

The induced voltage was an average value from ten times experiment results as shown in Table 2. The electric field obtained by dividing induced voltage with 2.54 , as calibrating factor to get electric field in unit of $\mathrm{V} / \mathrm{cm}$. Table 2 shows the highest induced voltage was only $1 \mathrm{~V}$ inside UAV compartment. It was measured at striking point on wing with impulse voltage $150 \mathrm{kV}$. The electronic equipment placed inside the compartment, such as: APS, GPS, telemetry and camera, has impulse breakdown voltage below hundreds volts. An electronic device with IC bipolar technique has $100 \mathrm{~V}$ as a lowest breakdown voltage limit [15]. Therefore, the highest measured voltage of $1 \mathrm{~V}$ did not damaged to the equipment.

Table 2. Measured Result of Induced Voltage And Electric Field when Flashover Occur between HV Electrode and UAV

\begin{tabular}{cccc}
\hline Striking Points & Impulse Voltage $(\mathrm{kV})$ & Induced Voltage $(\mathrm{V})$ & Electric Field $(\mathrm{V} / \mathrm{cm})$ \\
\hline Fuselage & 100 & 0 & 0 \\
& 150 & 0 & 0 \\
Nose & 100 & 0 & 0 \\
& 150 & 0 & 0 \\
Wing & 100 & 0 & 0 \\
& 150 & 1 & 0.39 \\
\hline
\end{tabular}

Figure 5(a) shows burning holes found at surface of aluminum foil during measurement. In order to the prevent physical damaged the thickness of the foil was increased to $0.3 \mathrm{~mm}$. Increasing the thickness is to increase flash point of material. The lowest temperature at which aluminum foil will ignite becomes higher. Figure $5(b)$ displays no burning hole on the surface of $0.3 \mathrm{~mm}$ aluminum foil.

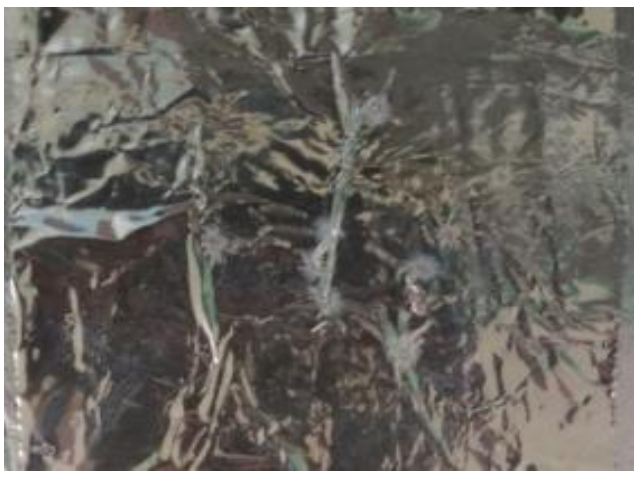

(a)

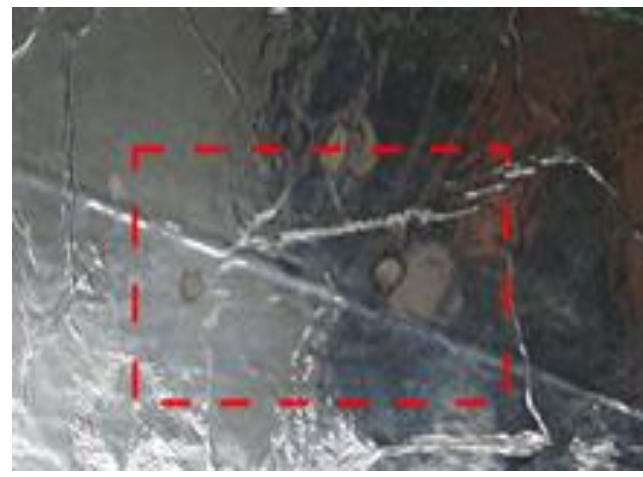

(b)

Figure 5. Direct effect of lightning strike: (a) The surface of $0.15 \mathrm{~mm}$ aluminum foil with burning hole (b) The surface of $0.3 \mathrm{~mm}$ aluminum foil without burning hole

\subsection{Testing Electric Field in Vicinity Area of UAV during Flashover}

The induced voltage and electric field measured at $4 \mathrm{~cm}$ below UAV are $456 \mathrm{~V}$ and $179.53 \mathrm{~V} / \mathrm{m}$, respectively. Theoretically the electric field is inversely proportional to the distance. The distance between compartments to the striking points on the exterior surface of UAV was assumed around $1 \mathrm{~cm}$. Hence, the calculated result of induced voltage and electric field should be four times higher than those measured at distance of $4 \mathrm{~cm}$. The induced voltage and electric field were $718 \mathrm{~V} / \mathrm{m}$ and $1824 \mathrm{~V}$, respectively.

The calculated induced voltage inside compartment of UAV was $1824 \mathrm{~V}$. The measured voltage inside compartment of UAV without electromagnetic interference shielding presume comparable with the calculated ones. The voltage could be harmful to the electronic equipment inside the compartment since it is higher than $100 \mathrm{~V}$ as the maximum insulation voltage of electronic equipment. Table 2 shows the measured induced voltage with electromagnetic 
interference shielding was only $1 \mathrm{~V}$ at UAV compartment when the impulse voltage in $150 \mathrm{kV}$. This result proved that the electromagnetic shielding successfully reduced the effect of electromagnetic interference due to lightning strike.

\section{Conclusion}

This paper proposed an electromagnetic interference shielding by covering body of UAV with aluminum foil thickness $0.15 \mathrm{~mm}$. The measured induced voltage and electric field in the compartment with electromagnetic interference shielding was far below the insulation voltage of the equipment. The pyhsical damage on the surface of aluminum foil can be avoided by increasing the thickness to $0.3 \mathrm{~mm}$. The EMI shileding are mandatory to prevent direct and indirect effect of lightning strike in UAV.

\section{References}

[1] Cai G, Lum KY, Chen BM, Lee TH. A brief overview on miniature fixed-wing unmanned aerial vehicles. Control and Automation (ICCA), 2010 8th IEEE International Conference. 2010: 285-290.

[2] Gou J, Tang Y, Liang F, Zhao Z, Firsich D, Fielding J. Carbon nanofiber paper for lightning strike protection of composite materials. Composites Part B: Engineering. 2010 Mar; 41(2): 192-8.

[3] Chemartin L, Lalande P, Peyrou B, Chazottes A, Elias PQ, Delalondre C, et al. Direct Effects of Lightning on Aircraft Structure: Analysis of the Thermal , Electrical and Mechanical Constraints. 2012; (5): 1-15.

[4] Yinghui Z, Shangchen F, Lihua S, Qing S, Zhengyu H. Experiment research of CFRP destroyed by lightning current. Lightning Protection (ICLP), 2014 International Conference o. Shanghai. 2014: 1303-1306.

[5] Gagné M, Therriault D. Lightning strike protection of composites. Progress in Aerospace Sciences. 2014; 64: 1-16.

[6] Thomassin JM, Jerome C, Pardoen T, Bailly C, Huynen I, Detrembleur C. Polymer/carbon based composites as electromagnetic interference (EMI) shielding materials. Materials Science and Engineering: R: Reports. 2013; 74(7): 211-32.

[7] Rehbein J, Wierach P, Gries T, Wiedemann M. Improved electrical conductivity of NCF-reinforced CFRP for higher damage resistance to lightning strike. Composites Part A: Applied Science and Manufacturing. 2017; 100: 352-60.

[8] Zhang B, Soltani SA, Le LN, Asmatulu R. Fabrication and assessment of a thin flexible surface coating made of pristine graphene for lightning strike protection. Materials Science and Engineering: B. 2017; 216: 31-40.

[9] Liu ZQ, Yue ZF, Wang FS, Ji YY. Optimizations of Flame Spraying Aluminum Thickness and Laminate Plies for Composite Lightning Protection. Advanced Materials Research. 2014; 915-916: 698-703.

[10] Rajesh PS, Sirois F, Therriault D. Damage response of composites coated with conducting materials subjected to emulated lightning strikes. Materials \& Design. 2018; 139: 45-55.

[11] Katunin A, Krukiewicz K, Herega A, Catalanotti G. Concept of a Conducting Composite Material for Lightning Strike Protection. Advances in Materials Science. 2016; 16(2): 32-46.

[12] Kawakami H, Feraboli P. Lightning strike damage resistance and tolerance of scarf-repaired meshprotected carbon fiber composites. Composites Part A: Applied Science and Manufacturing. 2011; 42(9): 1247-62.

[13] Cabello MR, Fernandez S, Pous M, Pascual-Gil E, Angulo LD, Lopez P, et al. SIVA UAV: A Case Study for the EMC Analysis of Composite Air Vehicles. IEEE Transactions on Electromagnetic Compatibility. 2017; 59(4): 1103-13.

[14] Garcia SG, Silva F, Escot D, Pascual E, Pantoja MF, Riu P, et al. UAVEMI project: Numerical and experimental EM immunity assessment of UAV for HIRF and lightning indirect effects. Proceedings of 2016 ESA Workshop on aerospace EMC. Valencia. 2016: 1-5.

[15] Peter Hasse. Overvoltage Protection of Low Voltage Systems. 2nd editon. The Institution of Engineering and Technology. 2008. 